\title{
Community-Based Monitoring of Tropical Forest Crimes and Forest Resources Using Information and Communication Technology - Experiences from Prey Lang, Cambodia
}

\author{
Søren Brofeldt*, Dimitrios Argyriou*, Nerea Turreira-García*, Henrik Meilby*, \\ Finn Danielsen ${ }^{\dagger}$ and Ida Theilade*
}

The use of smartphones for data collection has opened up new opportunities for communities wishing to engage in community-based monitoring. While information and communication technology (ICT) is able to systematize data collection, complex functions and observation types can present challenges for community members. ICT also may skew community participation towards young men, as they are sometimes more comfortable using smartphones.

This study investigates the success and cost-effectiveness of having local forest monitors use ICT to collect data on forest crimes and forest resources in Prey Lang, Cambodia. A workshop was held with the Prey Lang Community Network to identify the resources and illegal activities to be monitored. Guided by the community members, a smartphone app was subsequently developed and a total of 36 community members were trained in its use. We examined the extent to which the capacity of community members to collect data was dependent upon the complexity of the ICT and on their age and gender. We also assessed the costs of the monitoring program over a two-year period.

The community members were able to collect large amounts of data regardless of their gender or age. They made 10,842 entries of data on illegal logging and forest resources. Increased complexity of the app had no impact on the proportion of quality data collected. The cost of monitoring resembled other community-based monitoring programs but was notably less than for monitoring by professional foresters. Our findings suggest that local communities with little formal education are able to monitor forest crimes and forest resources cost-effectively using ICT; however, while the documentation collected was highly valuable, software and hardware maintenance, along with the digital data validation process, will continue to require external support.

Keywords: Illegal logging; forest resources; data quality; Prey Lang; smartphones; costs

\section{Introduction}

With the expansion of community-based natural resource management in tropical forests (Colchester 1994), community-based monitoring (CBM) of forests has received increasing interest from researchers and forestry professionals. Research has focused on a wide range of topics, for example: Community-based forest inventories in community forests (Carter 1996); community-based biodiversity monitoring in protected areas (Folke et al. 2004; Danielsen et al. 2007; Burton 2012; Fernández-Llamazares et al. 2016); and participatory monitoring in Reduced Emissions from Deforestation and Forest Degradation (REDD+) (Skutsch et al. 2011; Danielsen et al. 2013a;

\footnotetext{
* University of Copenhagen, DK

+ Nordic Agency for Development and Ecology, DK

Corresponding author: Ida Theilade (idat@ifro.ku.dk)
}

Brofeldt et al. 2014) and other payments for ecosystem services programs (Lewis and Nkuintchua 2012; Ens 2012; Vergara-Asenjo et al. 2015).

A recurring consideration has been the pros and cons of varying degrees of community and professional involvement in monitoring programs and the capacity of local communities. A number of studies have suggested typologies for defining the level of community involvement, ranging from marginal participation in data collection to full community control of design as well as data collection, analysis, and reporting (Danielsen et al. 2009; Shirk et al. 2012; Brammer et al. 2016). Requirements for capacity are limited in programs with a low level of community involvement. Here community members are often employed as guides or assistants, contributing skills that are expected to pre-exist in the community, such as knowledge of local terrain and the local biome. With increasing level of community involvement, local people must acquire new skills 
such as plot establishment and data recording, which are necessary for carrying out monitoring tasks (Danielsen et al. 2009). The capacity of local communities to learn and apply a standardized method as part of a systematic monitoring program and the validity of the data generated have been the subject of numerous studies (Whitelaw et al. 2003; Conrad and Hilchey 2011; Fernandez-Gimenez et al. 2008). So far, no consensus exists on whether limitations in community capacity to apply standardized monitoring methods affect the validity of the collected data, and if limitations should be accounted for in the design of methods.

This question has found renewed relevance with the emergence of information and communication technologies (ICT) as, in recent years, tablets and smartphones especially have been increasingly used in the field of forest monitoring, including CBM. While the use of ICT is less common in highly participatory projects (Brammer et al. 2016), a number of ICT tools have been developed specifically for CBM, including Cyber Tracker (Ens 2012), the Open Data Kit (Lewis and Nkuintchua 2012; Brammer et al. 2016), and the Sapelli Platform (Stevens et al. 2014). These tools commonly use smartphones or tablets as platforms for standardized data collection, which opens up new opportunities and challenges for communities and professionals wishing to engage in CBM. Experience suggests that using ICT in this way can help systematize data collection and minimize encoding errors, mitigating some of the concerns raised about community capacity to rigorously apply a standardized method (Dickinson et al. 2012; Kim 2014; Bellfield et al. 2015). Using ICT in collaborative monitoring systems also has been found to facilitate community involvement in data analysis and interpretation as well as implementation of subsequent management actions (Brammer et al. 2016). However, new issues emerge when using advanced technology in communities having limited experience with such devices. Navigating multiple functions and observation types especially has been mentioned as a critical challenge for communities in their efforts to apply ICT tools correctly (Ens 2012; Stevens et al. 2014). ICT also has been found to affect the long-term sustainability of CBM systems, as the continuous update and upkeep of phones and software necessitate the support of expensive external professionals (Danielsen et al. 2009; Brammer et al. 2016). Additionally, using advanced tools has been found to skew community participation towards young people and males, as males have considered themselves more technically capable (Caceres et al. 2012) and young people have tended to be more comfortable with using smartphones (Brammer at al. 2016; Lewis and Nkuintchua 2012; Stevens et al. 2014). Recent studies indicate that CBM can provide reliable data on forests (Danielsen et al. 2013a; Brofeldt et al. 2014; VergaraAsenjo et al. 2015). However, all these studies have used simple methods for data collection. The potential effects of information technology on data quality and the actual potential for the technology in monitoring of forests have remained unexplored.

Limited experience exists on the costs of using ICT for CBM of forests, within a context of high community involvement. On-the-ground forest monitoring is labor intensive and has traditionally been associated with high recurrent cost (Thompson et al. 2013). Several studies have documented the cost effectiveness of CBM of forests (Larrazabál et al. 2012; Danielsen 2013a; Zhao et al. 2016). Moreover, communities have been shown to experience a learning curve when monitoring is sustained over several years, further reducing costs as activities continue (Brofeldt et al. 2014). However, these studies have focused on CBM programs using simple methods and with relatively low levels of community involvement (as described by Danielsen et al. 2009 and Shirk et al. 2012). During all these studies, the participants were supervised by professionals while undertaking the monitoring activities.

Here, we present the case of a community-led ICT-based CBM program that has been implemented collaboratively by a network of local communities and scientists to protect a forest area from illegal logging. We examine the ability of the communities to provide valid data on forest crimes and resources within this setting. We analyze effects of the complexity of the tools applied, and we estimate the costs of developing and operating the monitoring program. Our study aims to answer the following questions:

i. Do local communities have the capacity themselves, without regular supervision, to use ICT to collect valid information on illegal logging and forest resources?

ii. Does the complexity of the ICT tools affect the ability of community patrollers to use the tools?

iii. Does using ICT in monitoring programs preclude the participation of some segments of society such as women and elders?

iv. What is the cost to develop and implement an ICT based forest monitoring program?

Based on these questions, we discuss how the complexity of the ICT tool, and the capacity of the local communities, have affected the validity of the generated data, the level of community involvement in various steps of the monitoring, and the costs of the program. By discussing the potential for using ICT for CBM of forests we hope to further the understanding of effective environmental monitoring.

\section{Methods \\ Study site and context}

Cambodia is part of the Indo-Burma biodiversity hotspot (Mittermeier et al. 1999). Its forests are home to hundreds of rare and endemic species of plants and animals (Hayes et al. 2015). Cambodia also has one of the highest rates of deforestation in the world (Milne 2015), despite having Asia's most extensive protected area management systems on paper, with 32 protected areas covering more than $45,000 \mathrm{~km}^{2}$ (Theilade and de Kok 2015). After the suspension of the national logging concession system in 2001, which mostly operated outside protected areas (Anon 2004), the Cambodian government started granting economic land concessions inside protected areas. As of 2012, a total of 113 such concessions had been granted inside Cambodia's protected forests (ADHOC 2012; HRC 2012). Recent remote sensing of the forests by U.S. MODIS/FIRMS suggests that deforestation rates are as 
high inside Cambodia's protected areas as they are outside (Peter and Pheap 2015).

The focus of this study was a forest area named Prey Lang (see Figure 1) along with a monitoring program implemented by a network of local forest activists, the Prey Lang Community Network (PLCN), and scientists from the University of Copenhagen (UCPH). Prey Lang is the largest lowland evergreen forest complex in the Indo-Burma biodiversity hotspot (Hayes et al. 2015). The forest covers about 520,000 ha and supports more than 200,000 people, including Kuy indigenous communities as well as Khmers. The forest forms an integral part of the local culture, and most people in the area directly or indirectly derive their livelihood from it by collecting resin, building materials, medicine, and food from the forest (Jiao et al. 2015; Hayes et al. 2015). The PLCN was formed by local village groups in the 2000s to document illegal logging activities associated with economic land concessions granted in the forest in the years 2002 to 2007 but frequently operating outside their designated areas. Since 2009, the PLCN has been working voluntarily and independently through externally funded projects to protect Prey Lang, by undertaking its own forest patrols to intercept illegal loggers and to seize chainsaws and other logging equipment. The PLCN has advocated for Prey Lang's protection since 2004. It has called for the government to acknowledge PLCN and the local communities in Prey Lang as partners in the future management of the forest. The primary objective of the monitoring program featured in this study has been to support this advocacy effort by documenting the logging as well as the important biodiversity in Prey Lang.

In 2016, following pressure from PLCN and other grassroots organizations as well as a wide range of national and international institutions, Prey Lang was included in the national protected area network. Despite this, the Prey Lang area has, as of February 2017, remained the focus of large-scale conversion to agriculture and plantations (see Figure 1), and the forest itself has been the continued target of logging of high value timber species. Several violent conflicts have occurred as villagers are forcefully removed from their ancestral lands, sometimes by the military (Global Witness 2009). As of February 2017 (the end of this study), no reduction in illegal logging was found based on monitoring data. The PLCN has indicated that it will continue its patrols until actual protection is implemented by the government.

\section{Design and development of the app}

We held a five-day initiation workshop in August 2014 with 34 participants, selected by the PLCN and coming from all four Cambodian provinces in which the PLCN operates. We employed participatory mapping to identify forest areas used by communities and defined the overall aim of the monitoring program in a series of focus group discussions. In these discussions, we used free-listing to identify resources and activities to be monitored. Afterwards we grouped resources and activities into categories to guide the design of monitoring methods. We decided that the PLCN would have ownership of all produced monitoring data, and that no data could be shared without its permission. We selected a smartphone application

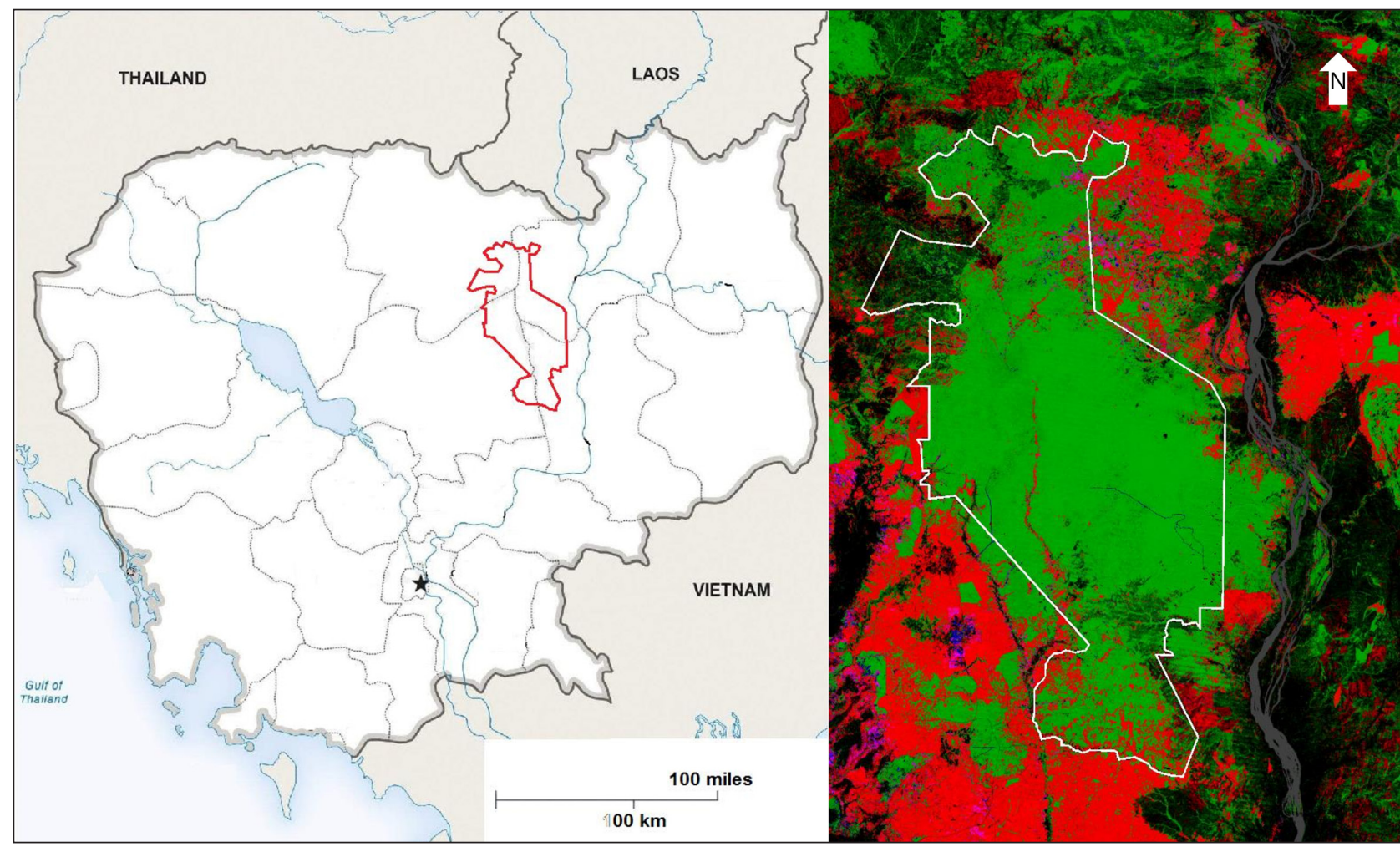

Figure 1: Cambodia's Prey Lang Wildlife Sanctuary (left) and classified satellite image (right) showing forest loss in years 2000 to 2016 (red), forest cover in 2016 (green), forest gain in years 2000 to 2016 (blue), both gain and loss in years 2000 to 2016 (purple), and other land uses (black). An asterisk shows the location of the capital city, Phnom Penh. Source: Global Forest Watch - University of Maryland; Hansen et al. 2013. 
based on the Sapelli Platform (see Stevens et al. 2014), developed specifically for use by local people with limited experience of technology, as the primary monitoring tool. The app was developed by a local IT company, based on the PLCN's input during the workshop and its feedback on a first prototype decision tree presented on the last day of the workshop.

The application, designated the "Prey Lang App" (henceforth the PLA), compiled three types of information: (i) Reference data. As soon as a new data point was created, metadata including time and date, GPS coordinates, and phone id was automatically attached to the observation. (ii) Primary documentation. Upon establishment of a new data point, the patroller documented the observation with a photo and an optional audio recording, using the smartphone's built in camera and recorder. (iii) Thematic tag. The patroller tagged the observation using a decision tree with three main categories: Illegal activities, Resources, and Reporting to authorities. Each main category had a number of pre-set sub-categories (see Appendix 1A, supplemental materials).

After registration of observations in the field, the data points were automatically uploaded to an online database via the cell phone network. Next, the data were validated by a database manager based on pre-established validation criteria (see Appendix 2, supplemental materials).

The first version of the PLA (Version 1) was designed to primarily collect quantitative information on a limited number of resources and interactions to minimize complexity and encourage systematic use during patrolling. Categories in the decision tree were all illustrated by pictures to allow participants with low literacy to navigate the PLA more easily. It was tested by a group of 40 PLCN members, using 20 Samsung Galaxy devices, at a sevenday field trial in December 2014. The field trial featured an initial three-day training course aimed at familiarizing the participants with the functionality of the PLA and smartphones in general, followed by a three-day field trial with various monitoring exercises. It concluded with a one-day evaluation of the PLA functionality and the monitoring experience. The consensus in the evaluation was that the version was too limited in scope, and a strong wish to be able to give qualitative descriptions of interactions was expressed. This input was used to inform the design of an updated version of the PLA (see Appendix 1B, supplemental materials), developed in January 2015. Data collection using this version (Version 2), running on 36 Samsung Galaxy devices, commenced in February 2015. This work was initiated in a seven-day field training course in Prey Lang, featuring a two-day refresher training focusing on familiarizing participants with the new functionality added to the PLA, followed by five days of supervised patrolling and monitoring in Prey Lang. This marked the beginning of actual data collection with the PLA.

Version 2 of the PLA was in service for 11 months, during which the PLCN continually provided feedback on functionality and operational challenges. This feedback was used to develop Version 3 of the PLA, which became operational in December 2015. This version featured a significantly extended decision tree as well as a number of bug fixes (see Appendix 1B, supplemental materials).
Version 3 operated for seven months until the release of Version 4 in August 2016. The guiding principle for all PLA updates was to fit the design of the application closer to the needs of the PLCN, and at the release of every new version, one- to two- day refresher trainings were conducted in the individual provinces to familiarize the PLCN patrollers with the added functionality.

In January 2017, 24 PLA users attended a two-day evaluation of the app and provided input for development of Version 5 (released in August 2017). The evaluation was conducted using individual questionnaires featuring open-ended questions on experiences that users had in working with the PLA and participating in the monitoring program. This was followed by a mediated plenum discussion of the questionnaire results and formulation of recommendations for the Version 5 design.

\section{The monitoring program}

In total, 36 patrollers were involved in monitoring using the PLA. They all were selected by the PLCN based on volunteerism and experience with either patrolling or using smartphones. In total, 30 male and 6 female PLCN members were involved, ranging from 18 to 61 years of age (see Appendix 3, supplemental materials).

The PLCN did the data collection with the PLA as part of existing patrolling activities. Since 2009, these have included regular and ad-hoc local forest patrols multiple times each month and large scale patrols, covering the Prey Lang core area, a couple of times per year (see Appendix 4, supplemental materials). Local patrols were organized by local PLCN members at regular intervals or in response to rumors of illegal activities in the local forest area. They were generally composed of 8 to 10 people on motorbikes or on foot (depending on the planned range of the patrol and the condition of the roads), and rarely targeted forest areas farther than $15 \mathrm{~km}$ from the villages where the involved PLCN members lived. The primary objective of these patrols was to discourage local level illegal logging by confiscating logging equipment and turning it over to the authorities, along with reports of recorded incidents. By using the PLA to record interactions with loggers, along with evidence of logging activity and important resources or biodiversity found, these local patrols were a central part of the PLA program. Large patrols were organized by a PLCN steering committee in collaboration with local PLCN core members, and generally targeted the Prey Lang core area, as this is far from most villages and thus rarely visited on local patrols. Large patrols served similar purposes as local patrols of discouraging logging and documenting illegal activities, but would also be announced in local and national media to raise awareness of the illegal logging in Prey Lang. The PLA was extensively applied during these patrols as well, as many PLA users participated. Data recorded with the PLA during both local and large patrols was compiled in quarterly monitoring reports by a team of data managers from the University of Copenhagen. The data were published in both English and Khmer and presented to the general public by PLCN members at press conferences held in Phnom Penh. These press conferences were an important part of the PLCN's overall advocating strategy for the protection of Prey Lang. 
Since 2009, PLCN members have received training in peace building and non-violence methods (as described by Galtung 1985). During all patrols, the PLCN used these methods when interacting with people found engaging in illegal activities. Despite the logging in Prey Lang being associated with a high level of conflict, no PLCN patroller carried any weapons, and the only security measures applied were patrolling in large groups and actively seeking to de-escalate heated encounters through dialogue.

\section{Data analysis}

Monitoring data spanning 24 months (1 Feb. 2015 until 31 Jan. 2017) were extracted from the database and analyzed using Excel. We refer to months by their sequential number (Feb 2015 being month 1, Mar 2015 being month 2 , and so on). The data were augmented by demographical data (age and gender - see Appendix 3, supplemental materials) on the 36 PLCN patrollers equipped with the PLA, and results from the evaluation with 24 PLA users conducted in January 2017.

Information on reasons for data validation and exclusion (see Appendix 2, supplemental materials) provided by the data managers was applied to assess the performance of the PLCN patrollers and the PLA, respectively. The term "validated entries" refers only to data that were validated by the data managers and included in reporting; "submitted entries" refers to all data submitted to the database; i.e., validated entries as well as entries that were excluded because of human error in the use of the PLA; "total entries" refers to all submitted entries, including those that were excluded because of technical errors with the app. Entries that were excluded by the data managers because of "relevance error" (see Appendix 2, supplemental materials) were omitted from the analysis.

Summaries of unique basic functions used to navigate the PLA and decision tree end points were counted for each version of the PLA. A "basic function" was defined as "a feature that differs from other features in the way it is operated by the user," i.e., camera and audio recording functions for documentation, push buttons, drop-down menus, free-writing fields for specifications, and numberpads for decision tree navigation. A "decision tree end point" was defined as "a possible unique end-point of the decision tree," i.e., individual tree species, NTFP, and animal species in the resource categories, or the individual types of activities that can be recorded (see appendices $1 \mathrm{~A}$ and $1 \mathrm{~B}$, supplemental materials).

For every month of the first two years of data collection, the numbers of validated and excluded entries (for human error and technical error, respectively) were tallied to visualize the impact of human error on the overall data collection. The total number of entries registered per day was tallied and compared to occurrences of events that might have influenced data collection (new PLA version releases and associated trainings as well as large-scale patrolling activities). To understand the role of app complexity, percentages of validated and excluded entries produced with each version of the PLA have been calculated for each PLA version and compared to the number of basic functions and decision tree end points featured in each version. The proportion of validated entries in submitted entries, as well as the average number of submitted entries, was calculated for age quartiles and genders to analyze the effect of these on how actively and successfully the PLA was used. A mixed logit model with random effects for individual patrollers and fixed effects for age groups and gender was used to detect any significant $(\mathrm{p}<0.05)$ differences between groups.

To calculate the costs of the monitoring program, we extracted costs from project accounts from the three main funding sources: DANIDA grant no. 104.N.491.IP, Alexander Soros Foundation, and Danmission operational support. We then divided costs into seven categories of activities: Development and management by UCPH; programming and support by the IT company; and material purchases, training activities, and patrolling grants used by the PLCN and local partners. Cost calculations were further subdivided into three project phases: Start-up phase (Aug. 2014 to Jan. 2015); $1^{\text {st }}$ year of monitoring (Feb. 2015 to Jan. 2016), and $2^{\text {nd }}$ year of monitoring (Feb. 2016 to Jan. 2017). We calculated costs in US dollars and converted from DKK based on the average exchange rate from 01 Aug 2014 to 01 Feb 2017 (\$0.159 US to 1 DKK). In cases where costs were hard to differentiate into the listed categories and phases (mainly salaries, as no detailed register of time spent on specific tasks existed), costs were divided based on task description in the Terms of Reference for the relevant positions. An extensive number of volunteers had been involved in training activities and data management at no costs. These were not accounted for in the calculation. In addition, patrolling costs incurred by the PLCN had not been recorded. The PLCN was issued a grant of $\$ 16,000$ US for patrolling in February 2015, but how much of this budget had been spent as of February 2017 is unknown. Costs for dissemination of monitoring results were excluded from the analysis. Lastly, cost for professional monitoring and CBM cited by Danielsen et al. (2005), used as a comparison in the discussion, has been adjusted for inflation between 2005 and 2017 (28.75\% according to the US bureau of labor statistics). ${ }^{1}$

For security reasons, all patrollers are presented anonymously in this study and no spatial data analysis has been included, as monitoring intensity around villages might enable pinpointing the locations of active PLCN communities.

\section{Results \\ Do local communities have the capacity to collect valid information using ICT? \\ We found that the community members of Prey Lang} Community Network had made 10,842 entries of data on observed forest resources and signs of illegal logging in the database over the 24 month period. A total of 4,560 entries $(42.1 \%)$ were successfully validated by the external data managers, whereas 1,303 entries $(12.0 \%)$ were excluded because of human error and 4,979 entries (45.9\%) were excluded because of technical error. The distribution of entries over time within the main categories provided in the decision trees is shown in Table 1, and examples of entries within the three main categories are found in Figure 2.

The rate of data production fluctuated between months, with more than five times as many entries in the most productive month ( $14^{\text {th }}$ month$)$ as in the least productive $\left(8^{\text {th }}\right.$ 
Table 1: Data on forest crimes and forest resources collected by the Prey Lang Community Network in Prey Lang, Cambodia, using the Prey Lang app from 1 Feb. 2015 till 31 Jan. 2017. Data are shown within the three main categories: Illegal activities (top), existing resources and biodiversity (middle), and interactions with authorities (bottom). For each category is shown the number of validated, human error rejected, and technical error rejected entries, along with the number of submitted entries (validated entries + human error rejected entries) and total entries (submitted entries + technical error rejected entries). $\%$ are percentages of the total number of entries.

\begin{tabular}{|c|c|c|c|c|c|c|c|c|c|c|}
\hline & \multicolumn{2}{|c|}{ Validated } & \multicolumn{2}{|c|}{$\begin{array}{c}\text { Human } \\
\text { error }\end{array}$} & \multicolumn{2}{|c|}{$\begin{array}{c}\text { Submitted } \\
\text { entries }\end{array}$} & \multicolumn{2}{|c|}{$\begin{array}{l}\text { Technical } \\
\text { error }\end{array}$} & \multicolumn{2}{|c|}{$\begin{array}{c}\text { Total } \\
\text { entries }\end{array}$} \\
\hline & $\mathbf{n}$ & $\%$ & $\mathbf{n}$ & $\%$ & $\mathbf{n}$ & $\%$ & $\mathbf{n}$ & $\%$ & $\mathbf{n}$ & $\%$ \\
\hline Logging evidence & 1,848 & 17.0 & 569 & 5.2 & 2,417 & 22.3 & 2,125 & 19.6 & 4,542 & 41.9 \\
\hline Logging interactions & 98 & 0.9 & 78 & 0.7 & 176 & 1.6 & 298 & 2.7 & 474 & 4.4 \\
\hline Mining, hunting and fishing & 35 & 0.3 & 37 & 0.3 & 72 & 0.7 & 192 & 1.8 & 264 & 2.4 \\
\hline Standing timber & 2,097 & 19.3 & 335 & 3.1 & 2,432 & 22.4 & 1,750 & 16.1 & 4,182 & 38.6 \\
\hline Biodiversity & 363 & 3.3 & 24 & 0.2 & 387 & 3.6 & 205 & 1.9 & 592 & 5.5 \\
\hline Reporting to authorities & 87 & 0,8 & 46 & 0.4 & 133 & 1.2 & 244 & 2.3 & 377 & 3.5 \\
\hline Other & 32 & 0.3 & 214 & 2.0 & 246 & 2.3 & 165 & 1.5 & 411 & 3.8 \\
\hline Total & 4,560 & 42.1 & 1,303 & 12.0 & 5,863 & 54.1 & 4,979 & 45.9 & 10,842 & 100 \\
\hline
\end{tabular}

and $18^{\text {th }}$ months; see Figure 3). On 588 days out of the 730 days in the two-year period ( $80.5 \%$ of days), at least one entry was recorded, with several spikes in data entry generation coinciding with large-scale patrolling activities. The relative number of entries excluded because of human error was considerably lower than the number of entries excluded because of technical error.

When asked their opinion on the monitoring program, 20 of the 24 patrollers who answered the questionnaire stated that they understood the PLA and felt that they were able to use it correctly (20 January 2017). Challenges associated with learning how to use new functionality added in Versions 3 and 4 came up during the plenum discussion of the questionnaire results. Eleven patrollers mentioned that it took them a few tries to navigate the updated decision tree end points and use the drop-down menus added in Version 3, which they concluded probably led them to upload some erroneous entries in the first months following the release of Version 3.

When asked to free-list challenges encountered and priorities for future PLA development, 16 patrollers specifically mentioned problems with uploading data as a key concern. They all mentioned the scarcity of areas with stable mobile phone connection in the provinces as a major cause of this, with one stating: "It is not possible to get a signal in my village and I have to travel to Thala Barivat [Stung Treng Province] to get a signal strong enough to upload my data. Therefore my phone memory is often full." (PLCN patroller)

\section{Does the complexity of the ICT tool affect the ability} of community patrollers to use it?

We found that, although the complexity increased with each new PLA version, the proportion of submitted entries successfully validated increased over time (Table 2). The number of entries excluded because of technical errors decreased slightly with the implementation of Version 3 (which included changes specifically designed to address data uploading issues experienced with Version 2), but remained high at around 40\% in Versions 3 and 4 . A summary of specific inputs and implemented changes to the PLA can be found in Appendix 1B, supplemental materials.

In the evaluation, 8 out of the 24 patrollers wished to have access to more functions, including the ability to take videos (in addition to photos and audio recordings), addition of maps to see areas of previous patrolling activity and satellite imagery of the forest, and addition of more species to the drop-down menus. In contrast, 2 patrollers thought the PLA (Version 4) had become too complex, both mentioning the introduction of drop-down menus to add specific species for trees, NTFPs, and animals in Version 3 as the function that is most difficult to use.

\section{Do age and gender affect the successful use of ICT in monitoring programs?}

We found no significant differences $(p>0.05$ - mixed logit model) in the proportion of validated entries produced between gender and age groups. A few patrollers in the age group 36-51 years had particularly high validation percentages, but the age group as a whole did not perform significantly better than the 19-24 year reference age group $(p=0.07)$. Older people tended to submit more entries than younger people, and men generally submitted more entries than women (Table 3).

How much does it cost to develop and implement an ICT-based monitoring system?

We found that, from the inception workshop in August 2014 to the end of the first two years of monitoring in February 2017, the cost of developing and operating the monitoring program was $\$ 136,634$ US (Table 4). This is equal to $\$ 0.26 \mathrm{US} / \mathrm{ha} /$ year and $\$ 29.96$ US per validated entry. Approximately one third of the total cost was spent by the PLCN and local partners ( $\$ 51,110$ US), one third by UCPH ( $\$ 45,253$ US), and one third by the IT company that developed the software $(\$ 39,915$ US). While PLA development was ongoing throughout all three phases, $45 \%$ of the total cost of the monitoring program was spent on 


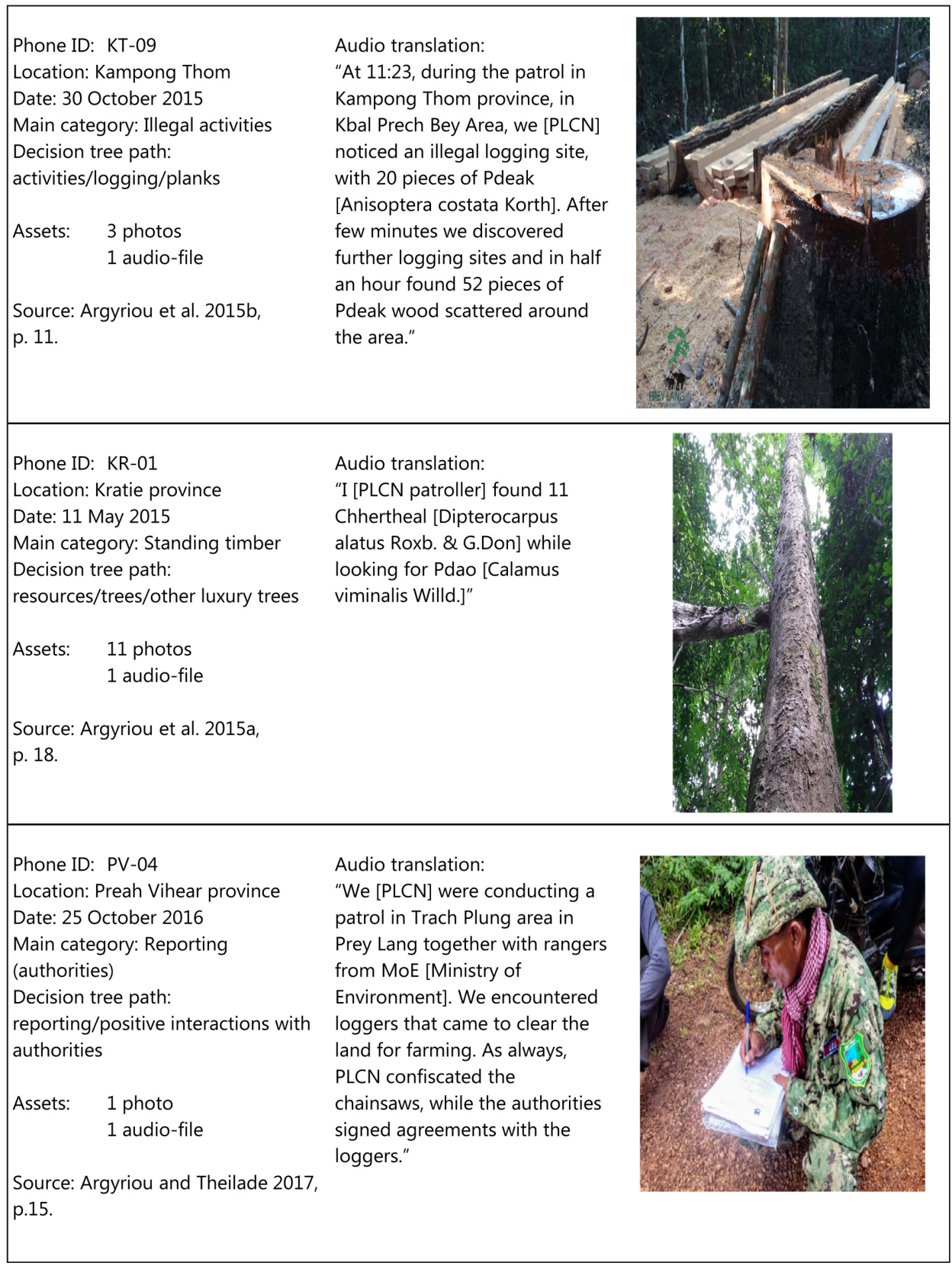

Figure 2: Three examples of validated data entries from the database about forest crimes and forest resources in Prey Lang, Cambodia, from each of the three main categories: Illegal activities, existing resources, and interactions with the authorities.

Table 2: Changes that have occurred within the 4 versions of the Prey Lang App in Prey Lang, Cambodia, 2015-2017. Shown are the number of unique decision tree end points available; the number of unique basic functions used (i.e., push button, drop down menu, camera, audio recording); the percentage of valid entries; the percentage of entries rejected due to human errors; and the percentage of entries rejected due to technical errors within the operation period for the associated version of the app. See also Appendix 1B, supplemental materials.

\begin{tabular}{lrrrr} 
Operation period & Version 1 & Version 2 & Version 3 & Version 4 \\
\cline { 2 - 5 } & None & $\begin{array}{c}\text { Month 1- } \\
\text { Month 11 }\end{array}$ & $\begin{array}{c}\text { Month 11- } \\
\text { Month 18 }\end{array}$ & $\begin{array}{c}\text { Month 18- } \\
\text { Month 24 }\end{array}$ \\
\hline Total unique decision tree end points & 34 & 614 & 1663 & 1663 \\
\hline Total unique basic functions & 4 & 9 & 9 & 10 \\
\hline Percent valid entries & $31 \%$ & $50 \%$ & $52 \%$ \\
Percent human error rejections & $14 \%$ & $10 \%$ & $8 \%$ \\
Percent technical error rejections & $55 \%$ & $40 \%$ & $40 \%$
\end{tabular}




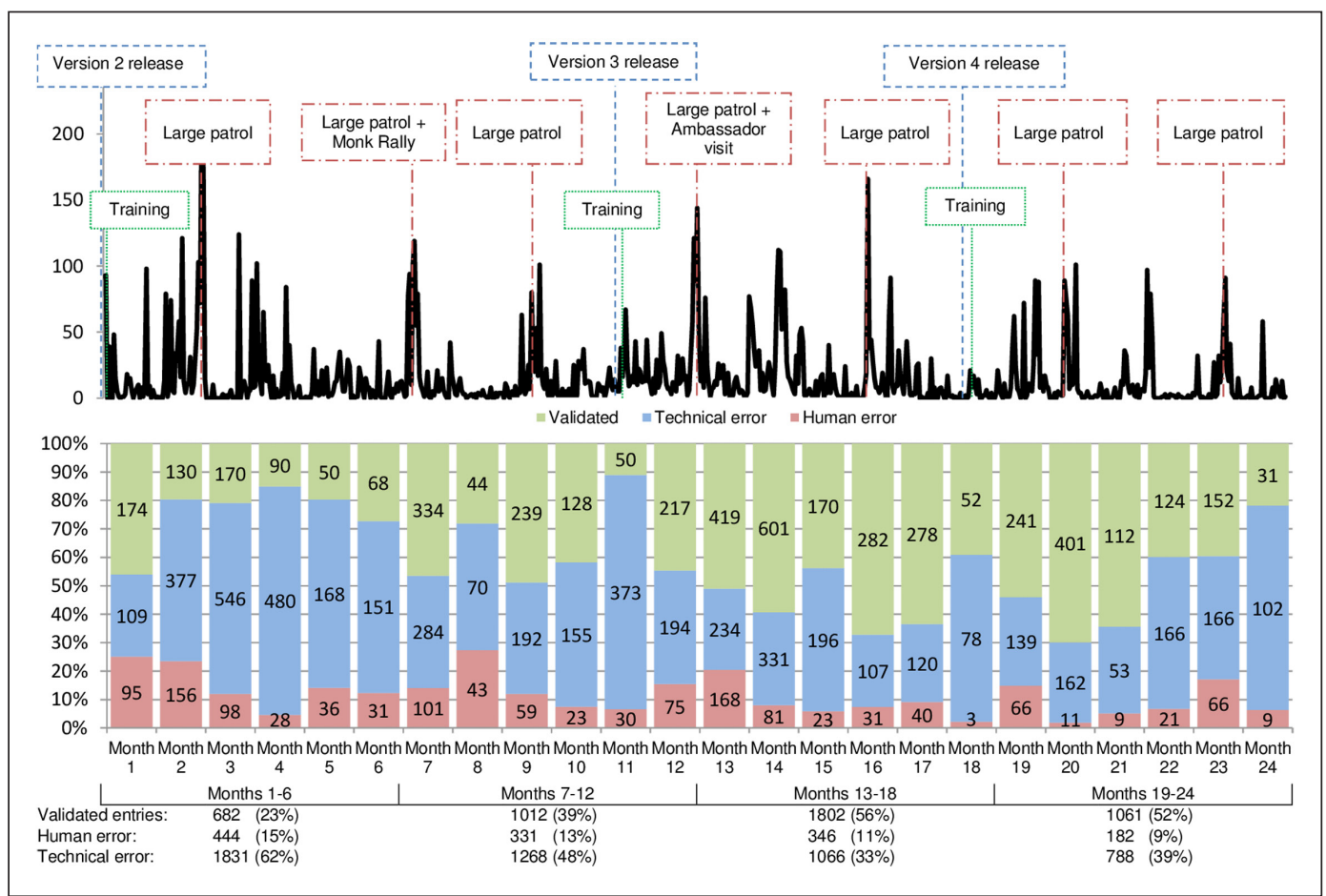

Figure 3: Data on forest crimes and forest resources collected by Prey Lang Community Network in Prey Lang, Cambodia, 2015-2017 ( $\mathrm{N}=10,842$ entries). The black line (top) shows the total number of entries recorded per day within each month and the timing of app version releases (blue), large organized patrols (red), and training sessions (green). Bars show monthly percentages (\%) of valid entries (green), entries excluded because of human error (blue), and entries excluded because of technical error (red), with the number of entries (n) within the three categories labeled on each bar.

Table 3: Entries on forest crimes and forest resources in Prey Lang, Cambodia, recorded by age groups and gender $(\mathrm{N}=36$ persons). Shown are average number of total entries of data per patroller and average proportion of valid entries out of submitted entries per age group and gender in the community monitoring program February 2015 to January 2017.

\begin{tabular}{lrrr}
$\begin{array}{l}\text { Age } \\
\text { group }\end{array}$ & $\mathbf{N}$ & $\begin{array}{c}\text { Average number of } \\
\text { total entries (std. dev.) }\end{array}$ & $\begin{array}{c}\text { Average percent of submitted } \\
\text { entries validated (std. dev.) }\end{array}$ \\
\hline $19-24$ & 9 & $212(103)$ & $71.5(13.9)$ \\
$25-35$ & 9 & $256(136)$ & $74.0(11.5)$ \\
$36-51$ & 9 & $341(148)$ & $84.4(9.2)$ \\
$52-61$ & 9 & $395(367)$ & $70.4(14.7)$ \\
\hline Female & 6 & $189(103)$ & $73.1(11.7)$ \\
Male & 30 & $324(230)$ & $75.5(13.7)$
\end{tabular}

PLA development (this figure does not include costs for training and consultation needed with the release of every new version of the PLA). The remaining costs were spent operating the monitoring program. Development costs increased by $16 \%$ from the first to the second year, while operation costs decreased by 15\% (see details in Appendix 5 , supplemental materials).

Many of the costs of operating the monitoring program were borne by the PLCN members who volunteered their time on patrols, at meetings, and for coordination of activities. These costs are not included in the cost calculations.

\section{Discussion \\ Validity of the data recorded}

Our results show that over a two-year period, the PLCN was able to produce 4,560 successfully validated data entries on forest resources and illegal logging in Prey Lang, constituting $42.1 \%$ of all entries submitted. The capacity of the PLCN to use the PLA correctly had a minor impact on the data with only $12.0 \%$ of entries being excluded because of human error as compared to the $45.9 \%$ discarded because of technical errors. The technical errors experienced were predominantly caused by the limited availability of mobile network coverage in the remote areas of Prey Lang, making it difficult to upload entries with multiple pictures. Other errors were related to bugs in the PLA that occurred during development (e.g., failure to include GPS coordinates of certain types of observations; scrambling of pictures when more than five pictures were added to a data point). While these software errors were mostly corrected with the releases of Versions 3 and 4, they still accounted for upwards of $10 \%$ of all technical errors recorded.

In all months, the number of entries excluded because of human error was considerably lower than the number 
Table 4: Costs of the community-based monitoring program with use of ICT in Prey Lang, Cambodia. Shown are actual costs incurred during the start-up phase (August 2014-January 2015) and in each of the two years of monitoring (February 2015-February 2017, in \$US, as of September 2017). PLA, Prey Lang App. UCPH, University of Copenhagen.

\begin{tabular}{lrrrr} 
& Start-up & $\mathbf{1}^{\text {st }}$ year & $\mathbf{2}^{\text {nd }}$ year & Total \\
\hline Development costs & 23,217 & 17,436 & 20,771 & 61,424 \\
\hline PLA development (UCPH) & 17,047 & 4,106 & 4,106 & \\
PLA programming (IT company) & 6,170 & 13,330 & 16,665 & \\
\hline Operating costs & 12,949 & 33,674 & 28,587 & 75,210 \\
\hline PLA support (IT company) & 0 & 1,875 & 1,875 & \\
Data management (UCPH) & 952 & 9,521 & 9,521 & \\
Materials & 9,141 & 3,237 & 3,237 & \\
Training and consultation & 2,856 & 11,041 & 5,954 & \\
Patrolling & 0 & 8,000 & 8,000 & \\
\hline & 36,166 & 51,110 & 49,358 & 136,634
\end{tabular}

of entries excluded because of technical errors (except months $1-3$ and 12-14). The errors in months 1-3 might be attributed to the patrollers' inexperience with the PLA. The release of Version 3 in month 11 (December 2015), which saw a large amount of functionality added to the PLA has, as mentioned by 11 patrollers in the evaluation, had a temporary effect on their ability to use the app correctly, and probably led to human errors in months 12-14. These observations, combined with the general decrease in prevalence of human error in entries over the two-year period, suggest that the patrollers went through a positive learning curve over time, similar to effects found in REDD+ community Monitoring Reporting and Verification (Brofeldt et al 2014). Moreover, we found no evidence that using ICT predisposes any particular demographic group to be better patrollers other than the finding that the age group 36-51 had some of the most capable patrollers of all. We also found no negative effect of app complexity on the ability of patrollers to use the PLA correctly. In contrast, the proportion of entries successfully validated increased with app complexity (Table 2). This is presumably because app development was slower than the learning rate achieved by PLCN members. Our findings suggest that the applied ICT technology's inherent main challenge, signal constraints when operating in a remote area with limited phone service, is a more significant constraint than the ability of community members to use the technology correctly. Similar limitations imposed by phone connectivity have been documented in application of ICT in rural farming systems in Ghana and Tanzania (Kalusopa 2005; Dhaka and Chayal 2010; Shah et al. 2014). Here it was found that limitation in phone connectivity was as severe a constraint to implementation as linguistic barriers (Shah et al. 2014) and lack of interest in using the tool among community members (Kalusopa 2005; Dhaka and Chayal 2010).

\section{Extent of community involvement}

The incorporation of the PLCN's input and priorities into the ongoing app development process has allowed for a continuous high level of community engagement in the monitoring. A large number of PLCN members were profoundly involved at several stages of the development, including both the conceptualization, design, implementation, and analysis steps. This level of community involvement is uncommon among CBM programs making use of ICT (Brammer et al. 2016). The collaboration between the PLCN and researchers from UCPH can be defined as collaborative monitoring with local data interpretation (sensu Danielsen et al. 2009 - "Type B" by Danielsen et al. 2013b and Brammer et al. 2016), with the addition that data interpretation was done collaboratively, as opposed to by the community independently. This was achieved by database managers from UCPH initially analyzing uploaded entries quantitatively and then presenting the results to the PLCN, who undertook interpretation of the presented data and the establishment of causal relationships; see Figure 4.

The work of the PLCN over the two-year period covered by this study also supports the findings by Brammer et al. (2016) that the participatory nature of the program and the use of digital devices assured reporting of management actions such as confiscation of logging equipment and illegally felled timber. Moreover, Brammer et al. (2016) found that CBM programs were more frequently reported as ongoing than programs not involving volunteers, but that employing digital data entry into the CBM program had a negative effect on the sustainability of monitoring programs. Our study supports the first finding, as PLCN had patrolled on a voluntary basis for more than a decade before the PLA was developed, but the introduction of ICT does not appear to have discouraged overall community participation. We believe that the sustainability is expedited by alignment of stakeholder objectives and the ease of using the PLA. Hence, our study supports the notion that innovative technologies attract interest, but the foundation of effective CBM depends more on collaboratively defined questions, objectives, conceptual models, and monitoring approaches. When this foundation is built through effective partnerships, digital data entry can enable the collection of more data of higher quality (Brammer et al 2016). 


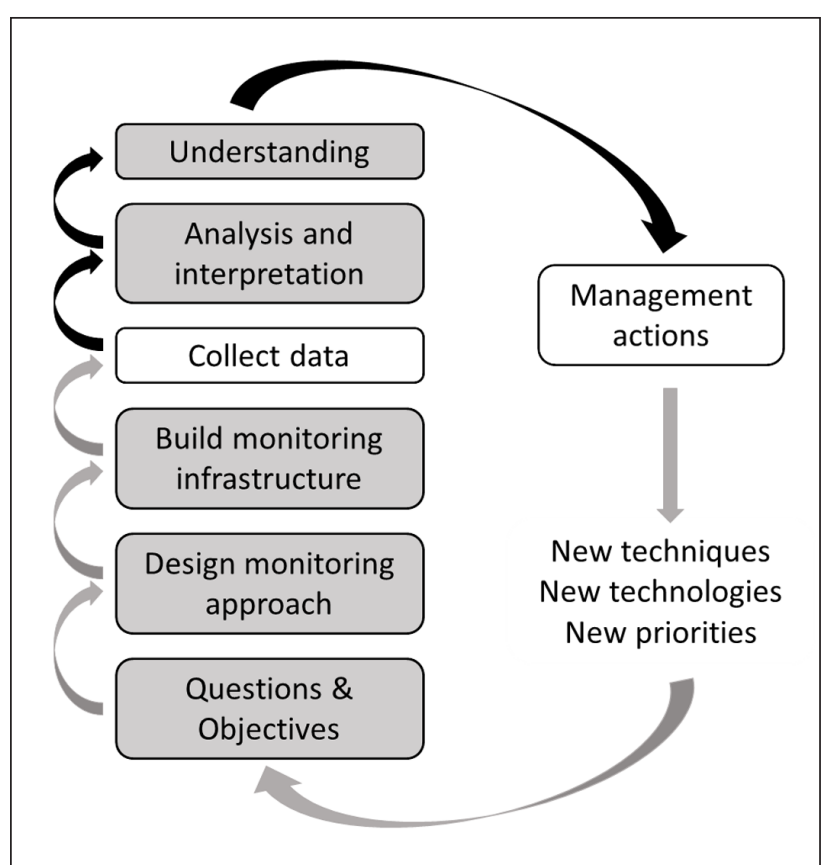

Figure 4: A schematic presentation of the communitybased monitoring program in Prey Lang, Cambodia, showing where ICT facilitated the monitoring process (black arrows). Local community contributions are in white, and a combination of community and university scientist contributions are in grey. Adjusted from Brammer et al. 2016, based on the spectrum of stakeholder participation in environmental monitoring approaches (Danielsen et al. 2009; 2013b), mapped onto a modified adaptive-monitoring framework (Lindenmayer and Likens 2009).

The increased complexity of the PLA with every new version of the software was based on PLCN specifically requesting additional functionalities. The learning that the patrollers have gained from their involvement in this process, and the associated ownership and commitment generated, are likely to have had a positive effect on the PLCN patrollers' ability and motivation to further develop their skills and apply the new functionality. This is in line with comments made by PLA users during the evaluation, that they felt their inclusion in app design had given them an increased understanding of how to use the app correctly. Ens (2012) found a similar benefit of involving local community monitors in the design of monitoring tools for rangelands in Australia.

While the PLA was an entirely new tool for the PLCN patrollers, it was incorporated into an existing patrolling paradigm that the patrollers were well familiar with. Some spikes in data generation (Figure 2) are likely caused by fluctuations in logging or small scale patrolling activity, while a number of periods of high entry generation appear to coincide with large patrols (see Appendix 4, supplemental materials). While both small and large scale monitoring activities generated many entries, 1,456 of entries (13.5\%) were generated on days with ten or fewer entries. These few entries are unlikely to have been generated during patrols, because even small scale local patrols generally feature a minimum of 15-20 entries recorded (assessment by PLCN patrol leader in private conversation during evaluation workshop in January 2017). Therefore, the entries are likely recorded by the PLCN patrollers using the PLA during their daily activities in the forest. In a ranger based monitoring program, where rangers do not necessarily live in the area or pursue monitoring activities while off duty, collecting data in this way would have been impossible. This suggests that the high level of community involvement brought with it an intrinsic benefit of CBM of forests-namely the constant presence of the PLCN in the area.

\section{Cost of the PLA monitoring program}

The PLA monitoring program cost of $\$ 0.26$ US/ha/year is notably lower than costs found for similar monitoring programs implemented by professional rangers $(\$ 4.60$ US/ha/year found by A. McNeilage; cited in Danielsen et al. 2005) but slightly above the median cost of $\$ 0.10$ US/ha/year found by Danielsen et al. (2005; inflation-adjusted figures) in a review of thirteen CBM projects. Those projects took place at different locations and times than the PLA, which limits their applicability for direct comparison to the cost found using the PLA. They also all featured simpler monitoring methods, no (or very limited) use of ICT, and longer intervals between successive bouts of data collection, which might partly explain the higher cost of the PLA program. Nonetheless, this suggests that ICT-based CBM can be cost effective when compared to professional forest monitoring, but the development costs of the ICT tools generally makes ICT-based CBM more expensive than CBM done without the use of ICT. While the overall cost of the program did not change notably from the first to the second year, the operation costs dropped by $15 \%$, counterbalanced by a $16 \%$ increase in PLA development costs. The decreasing operating costs are consistent with previous findings, indicating that increases over time in capacity, organization, and engagement of involved monitors lead to more cost-effective CBM (Brofeldt et al. 2014). This effect might have been more pronounced had the monitoring program been implemented outside the PLCN's existing patrolling activities, within a freshly formed community group. In many CBM programs (including the ones described by Brofeldt et al. 2014), community engagement and organization had to be developed from scratch, potentially incurring a greater initial operating cost than in the present study. The development costs in both years predominantly went to the involvement of $\mathrm{UCPH}$ and the web developers, for developing the four versions of the PLA, maintaining the app, and managing the data. While developing new PLA versions might not continue to be relevant, app maintenance and support for data management will remain necessary for as long as the CBM program is running. This significantly increases the reliance of the PLCN on outside support. The importance of independence from this type of outside support for the sustainability of a CBM program is well documented (Danielsen et al. 2005; Becker et al. 2005; Ens 2012; Brammer et al. 2016), and in the case of the PLCN's work in Prey Lang, is a tradeoff for the increased data quality achieved. 
Implications for the future management of Prey Lang Given the average human population density in the four Prey Lang provinces $\left(24.8 \text { people } / \mathrm{km}^{2}\right)^{2}$ and the continued occurrence of logging activities, managing the forest as a protected area will require monitoring of the illegal activities and enforcement of the forest protection. The increasing proportion of successfully validated reports on forest resources and illegal logging generated by the PLCN using the PLA is promising. During the inception workshop in August 2014, project partners discussed whether to incorporate the registration of count per unit effort (CpUE) into the monitoring program to allow for quantification of results despite various levels of monitoring intensity. This idea was rejected by the PLCN, as it did not feel that it would be necessary for its monitoring objectives. Members also thought that it would be hard to adopt into existing patrolling routines. If Prey Lang management required quantifiable information of resources or activities, adopting a CpUE into the PLA program would however be possible, although other studies have questioned the necessity of effort-corrected information on forest protection (Gray and Kalpers 2005).

The PLCN has repeatedly communicated to the Cambodian government its willingness to undertake monitoring of Prey Lang in exchange for involvement in forest management decision making and recognition of its forest rights (Argyriou et al. 2015a; 2015b; Argyriou et al. 2017). Several studies have documented the benefits to forest protection of community involvement in monitoring and management (Chazdon 2008; Agrawal and Angelsen 2009; Somanathan et al. 2009; Danielsen et al. 2011). However, successful protection of the forest will require establishing government-recognized local land rights, because distrust between communities and the local authorities may otherwise continue to undermine any benefits for both communities and forest protection (Mahanty et al. 2013; Pham et al. 2014).

Without PLCN's CBM program, monitoring of illegal logging and forest resources in Prey Lang would not be occurring. However, the PLCN will be unlikely to continue the ICT-based monitoring efforts without financial support for database management, purchasing of equipment, maintenance of the app, and analyses and reporting of the results. The low monitoring cost achieved by the PLCN despite its dependence on outside support for PLA development and operation could be an argument for their future involvement in management of Prey Lang as a protected area. Whatever the future funding available for management of Prey Lang as a protected area, a cost-effective monitoring system will be important for managing pressure on the forest from destructive activities.

\section{Conclusion}

We found that local communities were able to produce large amounts of validated data on forest crime and important forest resources using a smartphone application. They did this at a cost that was only slightly higher than costs in previous CBM programs not using ICT. Over the course of the two-year period examined, the complexity of the smartphone app increased considerably, but this did not negatively impact the quality of data produced. Instead, the data quality increased. Moreover, it emerged that women and elders were (at least) as capable of using the app as young men.

Like other studies, we found that it was fundamentally important to incorporate local knowledge, objectives, and priorities stemming from experience with forest patrolling into the design of the monitoring system (Berkes et al. 2000; Danielsen et al. 2009; Ens 2012). This required profound local involvement in the design of the ICT tool as well as in the planning and execution of the monitoring activities. Compared to the situation before this program, the use of ICT increased the reliance on external support for development and maintenance of the app and provision of smartphones, which over time may compromise the sustainability of the community-based monitoring program. However, if the PLCN becomes formally recognized by the Government of Cambodia as co-managers of the Prey Lang Wildlife Sanctuary, the Prey Lang app would be an important asset helping the communities to collect and analyze large amounts of forest data that can inform management decisions.

The program demonstrates the capacity of local communities to initiate, design, and implement monitoring programs using highly complex tools to collect valid information on a wide range of forest activities and resources. Such monitoring programs could be highly valuable for protected area management across the tropics and for global conservation and climate change mitigation efforts.

\section{Notes \\ ${ }^{1}$ https://www.bls.gov/data/inflation_calculator.htm accessed October 11, 2017. \\ 2 http://redatam.org/redkhm/census/khm2008/ accessed September 18, 2017.}

\section{Additional Files}

The Additional Files for this article can be found as follows:

Appendix 1A. PLA decision tree (Version 3 and 4). DOI: https://doi.org/10.5334/cstp.129.s1

- Appendix 1B. List of basic functions and decision tree end points within the three main categories for each version of the PLA. DOI: https://doi.org/10.5334/ cstp.129.s2

- Appendix 2. Summary of the data management protocol applied by the UCPH data managers. DOI: https://doi.org/10.5334/cstp.129.s3

- Appendix 3. Summary of demographics for the 36 patrollers equipped with the PLA. DOI: https://doi org/10.5334/cstp.129.s4

- Appendix 4. Timeline of events in the PLA development process. DOI: https://doi.org/10.5334/ cstp.129.s5

- Appendix 5. Detailed summary of costs (\$US) of PLA development and operation. DOI: https://doi. org/10.5334/cstp.129.s6 


\section{Acknowledgements}

This study was conducted with the support and permission of the Prey Lang Community Network (PLCN). All data produced with the Prey Lang App (PLA) is the specific property of the PLCN and is used in this publication with its expressed permission. We are grateful to all the people from the PLCN and the PLA users who kindly allowed us to work with them and be part of the efforts to save Prey Lang - a true natural wonder. Special thanks go to Narith Nou, Sithuan Chin, and Ernst Jürgensen from Danmission for their invaluable help. Thanks also go to Mary LüthyHui, Christoph Lüthy, and the rest of the team from Web Essentials for their input in the app development process. Lastly, thanks are due to DANIDA, Alexander Soros Foundation, and Danmission for funding the project "Prey Lang - it's our forest too" (104.N.491.IP) and the general work of the PLCN.

\section{Competing Interests}

The authors have no competing interests to declare.

\section{References}

ADHOC. 2012. The Report of Land and Housing Rights 2011. Cambodian Human Rights and Development Association (ADHOC), Phnom Penh, Cambodia.

Agrawal, A and Angelsen, A. 2009. Using community forest management to achieve REDD+ goals. Realising REDD+: National strategy and policy options, 1: 201-212.

Anonymous. 2004. Independent Forest Sector Review: The Forest Sector in Cambodia. Report to the Government of Cambodia.

Argyriou, D, Lauridsen, N, Dyrmose, AM and Brofeldt, S. 2015a. The current status of Prey Lang. 1st Monitoring report with information from PLCN patrolling. On behalf of PLCN - Copenhagen University.

Argyriou, D, Theilade, I and Graham, D. 2017. Prey Lang: The current status - 6th Monitoring report. On behalf of PLCN - Copenhagen University.

Argyriou, D, Tistan, A, Theilade, I, Vogt, C, Turreira Garcia, N, Mitterhofer, P and Brofeldt, S. 2015b. The current status of Prey Lang. 3rd Monitoring report with information from PLCN patrolling. On behalf of PLCN - Copenhagen University.

Becker, CD, Agreda, A, Astudillo, E, Costantino, M and Torres, P. 2005. Community-based monitoring of fog capture and biodiversity at Loma Alta, Ecuador enhance social capital and institutional cooperation. Biodiversity and Conservation, 14(11): 2695-2707. DOI: https://doi.org/10.1007/s10531005-8402-1

Bellfield, H, Sabogal, D, Goodman, L and Leggett, M. 2015. Case study report: Community-based monitoring systems for REDD+ in Guyana. Forests, 6(1): 133156. DOI: https://doi.org/10.3390/f6010133

Berkes, F, Colding, J and Folke, C. 2000. Rediscovery of traditional ecological knowledge as adaptive management. Ecological applications, 10(5): 1251-1262. DOI: https://doi.org/10.1890/10510761(2000)010[1251:ROTEKA]2.0.CO;2
Brammer, JR, Brunet, ND, Burton, AC, Cuerrier, A, Danielsen, F, Dewan, K, Mulrennan, M, et al. 2016. The role of digital data entry in participatory environmental monitoring. Conservation Biology, 30(6): 1277-1287. DOI: https://doi.org/10.1111/cobi.12727

Brofeldt, S, Theilade, I, Burgess, ND, Danielsen, F, Poulsen, MK, Adrian, T, Kurniawan, Y, et al. 2014. Community monitoring of carbon stocks for REDD+: Does accuracy and cost change over time? Forests, 5(8): 1834-1854. DOI: https://doi.org/10.3390/ f5081834

Burton, AC. 2012. Critical evaluation of a long-term, locally-based wildlife monitoring program in West Africa. Biodiversity and Conservation, 21(12): 30793094. DOI: https://doi.org/10.1007/s10531-0120355-6

Cáceres, R, Belding, E, Parikh, T and Subramanian, L. 2012. Information and communication technologies for development. IEEE Pervasive Computing, 3: 12-14. DOI: https://doi.org/10.1109/MPRV.2012.46

Carter, J. 1996. Recent approaches to participatory forest resource assessment. Overseas Development Institute (ODI).

Chazdon, RL. 2008. Beyond deforestation: Restoring forests and ecosystem services on degraded lands. Science, 320(5882): 1458-1460.

Conrad, CC and Hilchey, KG. 2011. A review of citizen science and community-based environmental monitoring: Issues and opportunities. Environmental monitoring and assessment, 176(1): 273-291. DOI: https:// doi.org/10.1007/s10661-010-1582-5

Danielsen, F, Adrian, T, Brofeldt, S, van Noordwijk, M, Poulsen, MK, Rahayu, S, Budiman, A, et al. 2013a. Community monitoring for REDD+: International promises and field realities. Ecology and Society, 18(3). DOI: https://doi.org/10.5751/ES-05464-180341

Danielsen, F, Burgess, ND and Balmford, A. 2005. Monitoring matters: Examining the potential of locallybased approaches. Biodiversity and Conservation, 14(11): 2507-2542. DOI: https://doi.org/10.1007/ s10531-005-8375-0

Danielsen, F, Burgess, ND, Balmford, A, Donald, PF, Funder, M, Jones, JP, Child, B, et al. 2009. Local participation in natural resource monitoring: A characterization of approaches. Conservation Biology, 23(1): 31-42. DOI: https://doi.org/10.1111/j.15231739.2008.01063.x

Danielsen, F, Mendoza, MM, Tagtag, A, Alviola, PA, Balete, DS, Jensen, AE, Poulsen, MK, et al. 2007. Increasing conservation management action by involving local people in natural resource monitoring. Ambio, 36(7): 566-570. DOI: https://doi.org/10.1579/00447447(2007)36[566:ICMABI]2.0.CO;2

Danielsen, F, Pirhofer-Walzl, K, Adrian, T, Kapijimpanga, D, Burgess, ND, Jensen, PM, Bonney, R, Madsen, J, et al. 2013b. Linking public participation in scientific research to the indicators and needs of international environmental agreements. Conservation Letters 7, 12-24. DOI: https://doi.org/10.1111/ conl.12024 
Danielsen, F, Skutsch, M, Burgess, ND, Jensen, PM, Andrianandrasana, H, Karky, B, Phartiyal, P, et al. 2011. At the heart of REDD+: A role for local people in monitoring forests? Conservation letters, 4(2): 158-167. DOI: https://doi.org/10.1111/j.1755263X.2010.00159.x

Dhaka, BL and Chayal, K. 2010. Farmers' experience with ICTs on transfer of technology in changing agrirural environment. Indian Research Journal of Extension Education, 10(3): 114-118.

Dickinson, JL, Shirk, J, Bonter, D, Bonney, R, Crain, RL, Martin, J, Purcell, K, et al. 2012. The current state of citizen science as a tool for ecological research and public engagement. Frontiers in Ecology and the Environment, 10(6): 291-297. DOI: https://doi. org/10.1890/110236

Ens, EJ. 2012. Monitoring outcomes of environmental service provision in low socio-economic indigenous Australia using innovative CyberTracker Technology. Conservation and Society, 10(1): 42. DOI: https://doi. org/10.4103/0972-4923.92194

Fernandez-Gimenez, $\mathbf{M}$, Ballard, $\mathbf{H}$ and Sturtevant, V. 2008. Adaptive management and social learning in collaborative and community-based monitoring: A study of five community-based forestry organizations in the western USA. Ecology and Society, 13(2). DOI: https://doi.org/10.5751/ES-02400-130204

Fernández-Llamazares, Á., Díaz-Reviriego, I, Guèze, M, Cabeza, M, Pyhälä, A and Reyes-García, V. 2016. Local perceptions as a guide for the sustainable management of natural resources: Empirical evidence from a small-scale society in Bolivian Amazonia. Ecology and Society, 21(1). DOI: https://doi.org/10.5751/ ES-08092-210102

Folke, C, Carpenter, S, Walker, B, Scheffer, M, Elmqvist, T, Gunderson, L and Holling, CS. 2004. Regime shifts, resilience, and biodiversity in ecosystem management. Annual Review of Ecology, Evolution, and Systematics, 35. DOI: https://doi.org/10.1146/ annurev.ecolsys.35.021103.105711

Galtung, J. 1985. Twenty-five years of peace research: Ten challenges and some responses. Journal of Peace Research, 22(2): 141-158. DOI: https://doi. org/10.1177/002234338502200205

Global Witness. 2009. Cambodia: Country for sale. How Cambodia's elite has captured the country's extractive industries. A report by Global Witness, February 2009. www.globalwitness.org/en/reports/country-sale/

Gray, M and Kalpers, J. 2005. Ranger based monitoring in the Virunga-Bwindi region of East-Central Africa: A simple data collection tool for park management. Biodiversity and Conservation, 14(11): 2723-2741. DOI: https://doi.org/10.1007/s10531-005-8406-x

Hansen, MC, Potapov, PV, Moore, R, Hancher, M, Turubanova, S, Tyukavina, A, Kommareddy, A, et al. 2013. High-resolution global maps of 21st-century forest cover change. Science, 342(6160): 850-853. DOI: https://doi.org/10.1126/science.1244693

Hayes, B, Khou, E, Thy, N, Furey, N, Sophea, C, Holden, J, Seiha, H, Sarith, P, Pengly, L and Simpson, V. 2015.
Biodiversity Assessment of Prey Lang - Kratie, Kampong Thom, Stung Treng and Preah Vihear Provinces. USAID, Winrock International and Conservation International.

HRC-Human Rights Council. 2012. Report of the Special Sapporteur on the Situation of Human Rights in Cambodia: A Human Rights Analysis of Economic and Other Land Concessions in Cambodia. www.ohchr.org/ Documents/HRBodies/HRCouncil/RegularSession/ Session21/A-HRC-21-63-Add1_en.pdf [accessed 1 August 2017].

Jiao, X, Smith-Hall, C and Theilade, I. 2015. Rural household incomes and land grabbing in Cambodia. Land Use Policy, 48, 317-328. DOI: https://doi. org/10.1016/j.landusepol.2015.06.008

Kalusopa, T. 2005. The challenges of utilizing information communication technologies (ICTs) for the small-scale farmers in Zambia. Library Hi Tech, 23(3): 414-424. DOI: https://doi.org/10.1108/07378830510621810

Kim, SY. 2014. Democratizing mobile technology in support of volunteer activities in data collection. Ph.D. Thesis. Carnegie Mellon, Pittsburgh, Pennsylvania.

Larrazábal, A, McCall, MK, Mwampamba, TH and Skutsch, M. 2012. The role of community carbon monitoring for REDD+: A review of experiences. Current opinion in environmental sustainability, 4(6): 707-716. DOI: https://doi.org/10.1016/j.cosust.2012.10.008

Lewis, J and Nkuintchua, T. 2012. Accessible technologies and FPIC: Independent monitoring with forest communities in Cameroon. Participatory Learning and Action, 65(13): 151-165.

Lindenmayer, DB and Likens, GE. 2009. Adaptive monitoring: A new paradigm for long-term research and monitoring. Trends in Ecology \& Evolution, 24, 482-486. DOI: https://doi.org/10.1016/j.tree.2009. 03.005

Mahanty, S, Suich, H and Tacconi, L. 2013. Access and benefits in payments for environmental services and implications for REDD+: Lessons from seven PES schemes. Land Use Policy, 31, 38-47. DOI: https://doi. org/10.1016/j.landusepol.2011.10.009

Milne, S. 2015. Cambodia's unofficial regime of extraction: Illicit logging in the shadow of transnational governance and investment. Critical Asian Studies, 47(2): 200-228. DOI: https://doi.org/10.1080/14672715.20 15.1041275

Mittermeier, RA, Myers, N, Gil, PR and Mittermeier, CG. 1999. Hotspots: Earth's Biologically Richest and Most Endangered Terrestrial Ecoregions. Conservation International, Washington DC, USA and CEMEX, Mexico City, Mexico.

Peter, Z and Pheap, A. 2015. (Un)protected areas. Cambodia Daily, August 1, 2015. www.cambodiadaily. com/unprotectedareas/ [accessed 1 August 2017] and donor ad hoc working group, Phnom Penh, Cambodia.

Pham, TT, Moeliono, M, Brockhaus, M, Le, DN, Wong, GY and Le, TM. 2014. Local preferences and strategies for effective, efficient, and equitable distribution of PES revenues in Vietnam: Lessons for REDD+. Human Ecology, 42(6): 885-899. DOI: https://doi. org/10.1007/s10745-014-9703-3 
Shah, P, Gandhi, N and Armstrong, L. 2014. Mobile Applications for Indian Agriculture Sector: A case study.

Shirk, J, Ballard, H, Wilderman, C, Phillips, T, Wiggins, A, Jordan, R, Bonney, R, et al. 2012. Public participation in scientific research: A framework for deliberate design. Ecology and Society, 17(2). DOI: https://doi. org/10.5751/ES-04705-170229

Skutsch, M. (ed.) 2011. Community Forest Monitoring for the Carbon Market. Earthscan, London.

Somanathan, E, Prabhakar, R and Mehta, BS. 2009. Decentralization for cost-effective conservation. Proceedings of the National Academy of Sciences, 106(11): 41434147. DOI: https://doi.org/10.1073/pnas.0810049106

Stevens, M, Vitos, M, Altenbuchner, J, Conquest, G, Lewis, J and Haklay, M. 2014. Taking participatory citizen science to extremes. IEEE Pervasive Computing, 13(2): 20-29. DOI: https://doi.org/10.1109/ MPRV.2014.37

Theilade, I and de Kok, R. 2015. Editorial - The status of botanical exploration and plant conservation in Cambodia. Cambodian Journal of Natural History, 2: $117-120$
Thompson, OR, Paavola, J, Healey, JR, Jones, JPG, Baker, TR and Torres, J. 2013. Reducing emissions from deforestation and forest degradation (REDD+): Transaction costs of six Peruvian projects. Ecology and Society, 18: 17. DOI: https://doi.org/10.5751/ ES-05239-180117

Vergara-Asenjo, G, Sharma, D and Potvin, C. 2015. Engaging stakeholders: Assessing accuracy of participatory mapping of land cover in Panama. Conservation Letters, 8(6): 432-439. DOI: https://doi.org/10.1111/ conl.12161

Whitelaw, G, Vaughan, H, Craig, B and Atkinson, D. 2003. Establishing the Canadian community monitoring network. Environmental monitoring and assessment, 88(1): 409-418. DOI: https://doi. org/10.1023/A:1025545813057

Zhao, M, Brofeldt, S, Li, Q, Xu, J, Danielsen, F, Læssøe, SBL, Theilade, I, et al. 2016. Can Community Members Identify Tropical Tree Species for REDD+ Carbon and Biodiversity Measurements? PloS one, 11(11): e0152061. DOI: https://doi.org/10.1371/journal. pone. 0152061

How to cite this article: Brofeldt, S, Argyriou, D, Turreira-García, N, Meilby, H, Danielsen, F and Theilade, I. 2018. CommunityBased Monitoring of Tropical Forest Crimes and Forest Resources Using Information and Communication Technology - Experiences from Prey Lang, Cambodia. Citizen Science: Theory and Practice, 3(2): 4, pp.1-14, DOI: https://doi.org/10.5334/cstp.129

Submitted: 16 October 2017 Accepted: 08 August $2018 \quad$ Published: 21 September 2018

Copyright: (c) 2018 The Author(s). This is an open-access article distributed under the terms of the Creative Commons Attribution 4.0 International License (CC-BY 4.0), which permits unrestricted use, distribution, and reproduction in any medium, provided the original author and source are credited. See https://creativecommons.org/licenses/by/4.0/.

$\mathrm{u}[\quad$ Citizen Science: Theory and Practice is a peer-reviewed open access journal published by Ubiquity Press. 